necrosis of the jaws: a growing epidemic. Journal of Oral and Maxillofacial Surgery. 2003;61(9):1115-1117. doi:10.1016/S02782391(03)00720-1

3. Khan AA, Morrison A, Hanley DA, et al. Diagnosis and management of osteonecrosis of the jaw: a systematic review and international consensus. J Bone Miner Res. 2015;30(1):3-23. doi:10.1002/jbmr.2405

4. Cosman F, de Beur SJ, LeBoff MS, et al. Clinician's Guide to Prevention and Treatment of Osteoporosis. Osteoporos Int. 2014;25(10):23592381. doi:10.1007/s00198-014-2794-2

5. Abe T, Sato T, Kokabu S, et al. Zoledronic acid increases the circulating soluble RANKL level in mice, with a further increase in lymphocytederived soluble RANKL in zoledronic acid- and glucocorticoid-treated mice stimulated with bacterial lipopolysaccharide. Cytokine. 2016;83:17. doi:10.1016/j.cyto.2016.03.012

6. Yamazaki T, Yamori $M$, Yamamoto $K$, et al. Risk of osteomyelitis of the jaw induced by oral bisphosphonates in patients taking medications for osteoporosis: A hospital-based cohort study in Japan. Bone. 2012;51(5):882-887. doi:10.1016/j.bone.2012.08.115

7. Ruggiero SL, Dodson TB, Fantasia J, et al. American Association of Oral and Maxillofacial Surgeons Position Paper on Medication-Related Osteonecrosis of the Jaw-2014 Update. Journal of Oral and Maxillofacial Surgery. 2014;72(10):19381956. doi:10.1016/j.joms.2014.04.031

8. Hellstein JW, Adler RA. Managing the care of patients receiving antiresorptive therapy for prevention and treatment of osteoporosis. Recommendations from the American Dental Association Council on Scientific Affairs.2011.

9. Adler RA, El-Hajj Fuleihan G, Bauer DC, et al. Managing Osteoporosis in Patients on Long-Term Bisphosphonate Treatment: Report of a Task Force of the American Society for Bone and Mineral Research. J Bone Miner Res. 2016;31(1):16-35. doi:10.1002/jbmr.2708

\title{
KẾT QUẢ SớM PHẪU THUÂT NộI SOI TUYẾN GIÁP QUA TIỀN ĐİNH MIÊNG TRONG ĐIỀU TRI UNG THƯ TUYẾN GIÁP THỂ NHÚ TẠI BỆNH VIỆN K
}

\section{TÓM TẮT}

Tổng quan: Phẫu thuật nội soi cắt tuyến giáp qua tiên đình miệng (TOETVA) là kỹ thuật cắt tuyến giáp mới và ngày càng được áp dụng rộng rãi trong điều trị ung thư tuyến giáp trên thế giới. Tuy nhiên ở Việt Nam còn rất ít báo cáo về kết quả điêu trị ung thư tuyến giáp bằng cách tiếp cận này. Đối tượng và phương pháp nghiên cứu: Gồm 30 bệnh nhẩn được chẩn đoán ung thư tuyến giáp được phẫu thuật nội soi bằng phương pháp TOETVA tại Bệnh viện $\mathrm{K}$ từ tháng $5 / 2020$ đến tháng 5/2021. Kết quả: Đô tuổi trung bình là $29,3 \pm 7,4$. Tất cả bệnh nhân đều là nữ giới. U bên phải chiếm $56,7 \%$, bên trái chiếm 43,3\%. 26 BN cắt thuỳ, eo và vét hạch nhóm 6 với thời gian mổ trung bình là 105,5 phút. Chỉ có $4 \mathrm{BN}$ cắt toàn bộ tuyến giáp và vét hạch nhóm 6 hai bên với thời gian mổ trung bình là 140,5 phút. Các biến chứng ít gặp và đa số là tạm thời, hồi phục sau 3 tháng. Tất cả bệnh nhân đều hài lòng về kểt quả thẩm mĩ. Kết luận: TOETVA là một phương pháp an toàn, hiệu quả, đạt kết quả thẩm mĩ tối ưu và nên được áp dưng rộng rã̃i cho nhóm bệnh nhân phù hợp trên thực hành lâmm sàng.

Tư khoá: Toetva, phấu thuật nội soi, nội soi tuyến giáp, tiền đình miệng.

\footnotetext{
${ }^{1}$ Ngoại đầu cổ, Bệnh viện K

2 Trường Đai hoc Y Hà Nôi

Chịu trách nhiệm chính: Ngô Quốc Duy

Email: Duyyhn@gmail.com

Ngày nhận bài: 14.9.2021

Ngày phản biên khoa hoc: 15.11.2021

Ngày duyệt bài: 22.11.2021
}

Ngô Quốc Duy ${ }^{1,2}$, Ngô Xuân Quý ${ }^{1}$

\section{SUMMARY}

EARLY OUTCOMES OF TRANSORAL

\section{ENDOSCOPIC THYROIDECTOMY VESTIBULAR APPROACH IN MANAGEMENT OF PATIENTS \\ WITH PAPILLARY THYROID CANCER IN VIETNAM NATIONAL CANCER HOSPITAL}

Introduction: Transoral endoscopic thyroidectomy vestibular approach (TOETVA) is a novel remote-access endoscopic approach. This method has applied in treating thyroid cancer worldwide. Patients and Methods: From May 2020 to May 2021, we performed 30 transoral endoscopic thyroidectomies via the vestibular approach for papillary thyroid cancer. Clinical features and outcomes were analyzed from a prospectively maintained database.Results: The average age was $29,3 \pm 7,4$ years. All patients were female. A tumor located in the right lobe accounted for $56,7 \%$ and in the left lobe contribute to $43,3 \%$. 26 patients underwent hemithyroidectomy, ismuthectomy plus unilateral central neck dissection with 105,5 minutes for the mean operative time. While 4 patients had total thyroidectomy plus bilateral central neck dissection with 140,5 minutes for the mean operative time. The rate of complications was very low. All patients were highly satisfied with the surgical outcome, especially, cosmetic results. Conclusion: The TOETVA for treating papillary thyroid cancer is a safe and effective procedure. For selected patients, this technique is a viable alternative to conventional thyroidectomy. 
Keywords: TOETVA, endoscopic surgery, transoral endoscopic thyroidectomy, vestibular approach

\section{I. ĐẶT VẤN ĐỀ}

Ung thư tuyến giáp (UTTG) là bệnh hay gặp nhất trong các ung thư tuyến nội tiết (chiếm 9295\%), chiếm 3,6\% các bệnh ung thư nói chung, có xu hướng ngày càng gia tăng và trẻ hoá. Phẫu thuật đóng vai trò chính trong điêu trị ung thư tuyến giáp. Phẫu thuật nội soi cắt tuyến giáp qua tiên đình miệng (Transoral endoscopic thyroidectomy vestibular approach - TOETVA) là kỹ thuật cắt tuyến giáp mới. Phương pháp này có nhiều ưu điểm vượt trội so với các đường tiếp cận khác như an toàn, đường tiếp cận ngắn nhất, có thể tiếp cận cả hai thuỳ tuyến giáp, thuận lợi trong việc vét hạch cổ trung tâm và đặc biệt đạt kết quả thẩm mỹ cao nhất (hoàn toàn không có sẹo mổ) [1]. Tuy nhiên ở Việt Nam còn rất ít báo cáo về kết quả điêu trị ung thư tuyến giáp bằng cách tiếp cận này. Ở miền bắc Việt Nam, Bệnh viện $\mathrm{K}$ là cơ sở y tế đâu tiên áp dụng phương pháp này để điều trị ung thư tuyến giáp từ năm 2018. Do vậy, trong nghiên cứu này chúng tôi đánh giá đặc điểm bệnh nhân và kết quả phấu thuật sớm trong điều trị ung thư tuyến giáp thể nhú trên 30 bệnh nhân được áp dụng phương pháp TOETVA

\section{II. ĐỐI TƯợNG VÀ PHƯƠNG PHÁP NGHIÊN CỨU}

2.1. Đối tượng nghiên cứu: Gồm 30 bệnh nhân được chẩn đoán ung thư tuyến giáp được phẫu thuật nội soi bằng phương pháp TOETVA tại Bệnh viện $K$ từ tháng 5/2020 đến tháng 5/2021.

Tiêu chuẩn lựa chọn bệnh nhân:

- Kích thước tuyến giáp $<10 \mathrm{~cm}$

- Thể tích tuyến giáp $<45 \mathrm{~mm}^{3}$

- Kích thước $\mathrm{u}<6 \mathrm{~cm}$ với u lành và $<2 \mathrm{~cm}$ đối với ung thư

- Ung thư tuyến giáp thể nhú giai đoạn cT1NOMO

- Bệnh nhân có mong muốn đạt kết quả thẩm mỹ tối ưu

\section{Tiêu chuấn loai trừ:}

- BN không đủ tiêu chuẩn cho cuộc gây mê

- Tiền sử xạ trị vùng cổ, trung thất trên

- Đã phẫu thuật vùng cổ trước

- Cường chức năng tuyến giáp

- Áp xe khoang miệng

- Ung thư tuyến giáp thể tuỷ hoặc thể không biêt hoá.

\subsection{Kỹ thuật mổ nội soi tuyến giáp qua} đường miệng

- Chuẩn bị trước mổ: Bệnh nhân được dùng kháng sinh dự phòng trước mổ 30 phút bằng đường tĩnh mạch Amoxicillin $1 \mathrm{~g}$ và Metronidazole 500mg.

- Gây mê: Bệnh nhân được gây mê nội khí quản qua đường mũi.

- Tư thế bệnh nhân: Nằm ngửa, đâuu cố định với cổ duỗi tối đa có kê gối ở vai. Khoang miệng của bệnh nhân được sát khuẩn sạch bằng dung dich betadin

- Kỹ thuâat:

o Đường rạch niêm mạc: 3 đường được rạch ở giữa môi dưới và răng ở hàm dưới để đặt 3 trocars. Đường rạch đâu tiên nằm ngang, dài khoảng 10-15mm ở giữa môi dưới và răng hàm dưới. Hai đường rạch dài khoảng $5 \mathrm{~mm}$ ở bên đường rạch giữa.

o Đặt trocars: Trocas 10 mm được đặt ở giứa với áp lực bơm CO2 là 5-6mmHg. Trong khi đó 2 trocas $5 \mathrm{~mm}$ được đặt ở hai bên. Vị trí đặt 2 trocar $5 \mathrm{~mm}$ được đặt sát với hàm dưới để tránh làm tổn thương thân kinh cằm.

oTạo khoang phẫu thuật: Dùng đơn cực và dao siếu âm bóc tách tổ chức dưới da đến hõm ức và hai bên đến bờ trước cơ ức đòn chũm.

o Bộc lộ tuyến giáp và cắt tuyến giáp

- Mạc sâu được mở ở đường giữa và các cơ trước giáp được kéo sang hai bên bằng mũi kim khâu qua da xuyên vào cơ trước giáp kéo ra ngoài.

- Bộc lộ eo giáp và cắt eo giáp bằng dao siêu âm

- Bộc lộ thuỳ giáp có tổn thương và đánh giá tổn thương, tiến hành cắt thuỳ giáp trạng bằng dao siêu âm

- Trong trường hợp cắt thuỳ tuyến giáp cân tìm và bảo tồn tuyến cận giáp và thần kinh thanh quản quặt ngược trước.

o Vét hach cổ trung tâm bằng dao siêu âm

o Lây bệnh phẩm qua lỗ trocar $10 \mathrm{~mm}$

o Khâu lại đường giữa bằng chỉ Vicryl 3-0.

o Khâu lại đường rạch ở niêm mạc miệng bằng chỉ Vicryl 5-0.

\section{KẾT QUẢ NGHIÊN CỨU}

Qua tiến hành phẫu thuật 30 bệnh nhân bằng phương pháp TOETVA tại Bệnh viện $\mathrm{K}$ từ tháng 5/2020 đến tháng 11/2020. Chúng tôi rút ra một số kết quả như sau:

Đặc điểm nhóm bệnh nhân được phẫu thuật nội soi qua tiền đình miệng

\begin{tabular}{|c|c|c|}
\hline Đăcc điểm & $\begin{array}{l}\text { Kết } \\
\text { quả }\end{array}$ & $\begin{array}{c}\text { Tỷ lệ phân } \\
\text { trăm }\end{array}$ \\
\hline Tuổi bệnh nhân (tuối) & \multicolumn{2}{|c|}{$29,3 \pm 7,4(15-46)$} \\
\hline Giới (n): Nữ & 30 & $100 \%$ \\
\hline Nam & 0 & $0 \%$ \\
\hline \multicolumn{3}{|c|}{ Vị trí u (n) } \\
\hline
\end{tabular}




\begin{tabular}{|c|c|c|}
\hline Thuỳ phải & 17 & $56,7 \%$ \\
\hline Thuỳ trái & 13 & $43,3 \%$ \\
\hline \multicolumn{3}{|c|}{ Phương pháp phâu thuật (n) } \\
\hline $\begin{array}{l}\text { Cắt thuỳ, eo và vét } \\
\text { hạch nhóm } 6\end{array}$ & 26 & $86,7 \%$ \\
\hline $\begin{array}{l}\text { Căt toàn bộ tuyến giáp } \\
\text { và vét hach nhóm } 6\end{array}$ & 4 & $13,3 \%$ \\
\hline Kích thước u (mm) & \multicolumn{2}{|c|}{$7,4 \pm 3,3$} \\
\hline \multicolumn{3}{|c|}{ Đặc điếm nhóm bệnh nhân ung thư(n=5 } \\
\hline pT1a & 26 & $86,7 \%$ \\
\hline pT1b & 4 & $13,3 \%$ \\
\hline pN0 & 20 & $66,7 \%$ \\
\hline pN1a & 10 & $33,3 \%$ \\
\hline $\begin{array}{c}\text { Số lượng hạch vét } \\
\text { được TiB }\end{array}$ & \multicolumn{2}{|c|}{$4,9 \pm 2,9$} \\
\hline
\end{tabular}

Nhận xét: - Độ tuối trung bình là 29,3 37,4 .

Tất cả bệnh nhân đều là nữ giới, chiếm $100 \%$

- U bển phải chiếm $56,7 \%$, bên trái chiếm $43,3 \%$

- Giải phẫu bệnh: 100\% bệnh nhân ung thư tuyến giáp thể nhú.

- Có $86,7 \%$ BN cắt thuỳ, eo tuyến giáp và vét hach nhóm 6.

- U chủ yếu ở giai đoạn T1a (chiếm 86,7\%)

- Tỷ lệ di căn hạch sau mổ ở nhóm cT1NOMO là $33,3 \%$.

Kết quả phẫu thuật sớm trong điêu trị UTTG thể nhú tai Bênh viên $K$

\begin{tabular}{|c|c|}
\hline Đặc điếm & Kết quả \\
\hline \multicolumn{2}{|c|}{ Thời gian phâu thuật (phút) } \\
\hline $\begin{array}{l}\text { Cắt thuỳ, eo và vét hạch } \\
\text { nhóm } 6\end{array}$ & 105,5 \\
\hline $\begin{array}{c}\text { Cắt toàn bộ tuyến giáp và } \\
\text { vét hạch nhóm } 6\end{array}$ & 140,5 \\
\hline $\begin{array}{l}\text { Thời gian nằm viện } \\
\text { trung bình }\end{array}$ & $4,9 \pm 0,7$ (ngày) \\
\hline \multicolumn{2}{|c|}{ Biến chứng $(n, \%)$} \\
\hline Chảy máu & 0 \\
\hline Chuyến mố mở & 0 \\
\hline Khàn tiếng tạm thời & $2(6,7 \%)$ \\
\hline Khàn tiếng vĩnh viên & 0 \\
\hline Hạ canxi tạm thời & 0 \\
\hline Hạ canxi vĩnh viền & 0 \\
\hline $\begin{array}{c}\text { Tê bì cằm, môi dưới tạm } \\
\text { thời ( } \leq 3 \text { tháng) }\end{array}$ & $6(20 \%)$ \\
\hline $\begin{array}{c}\text { Tê bì cằm, môi dưới vĩnh } \\
\text { viến (> } 3 \text { tháng) }\end{array}$ & $1(3,3 \%)$ \\
\hline Thủng khí quản & 0 \\
\hline
\end{tabular}

Nhân xét: - 26 BN cắt thuỳ, eo và vét hạch nhóm 6 với thời gian mổ trung bình là 105,5 phút. Chỉ có $4 \mathrm{BN}$ cắt toàn bộ tuyến giáp và vét hạch nhóm 6 hai bên với thời gian mổ trung bình là 140,5 phút.

- Các biến chứng ít gặp và đa số là tạm thời, hồi phục sau 3 tháng.

\section{BÀN LUÂN}

Phẫu thuật tuyến giáp kinh điển với đường rạch da ở vùng cổ trước vẫn là cách tiếp cận cơ bản nhưng để lại vết sẹo dài vùng cổ trước ảnh hưởng đến thẩm mĩ và chất lượng cuộc sống người bệnh đặc biệt ở phụ nữ trẻ tuổi. Do đó, gần đây đã có nhiều phương pháp phẫu thuật mới ít xâm lấn trong phẫu thuật tuyến giáp, thay thế cho mổ mở truyền thống: phẫu thuật nội soi tuyến giáp đường nách vú 1 bên, đường vú 2 bên, đường sau tai được phát triển để hạn chế những nhược điểm trên. Tuy nhiên các phương pháp này chỉ thay đổi vị trí rạch da, ít nhiêu vẫn để lại sẹo trên cơ thể bệnh nhân.

Phẫu thuật nội soi cắt tuyễn giáp ít xâm lấn qua lỗ tự nhiên là một trong những phương pháp nội soi phổ biến đã được mô tả vào năm 2016 bởi Anuwong và đã được áp dụng tại một số nước trên thế giới, trong đó có Việt Nam [2]. So với các phương pháp khác, phương pháp này có ưu điểm riêng là ít xâm lấn hơn các phương pháp phẫu thuật nội soi khác, hoàn toàn không để lại sẹo trên da, tiếp cận cả 2 thùy tuyến giáp qua 1 đường mổ và thuận lợi trong việc vét hạch hạch cổ. Năm 2018, tác giả Lê Văn Quảng báo cáo trường hợp đầu tiên triển khai thành công kỹ thuật cắt tuyến giáp qua đường miệng [3]. Từ đó kỹ thuật này từng bước được áp dụng tại một số cơ sở y tế trong cả nước.

Đặc điểm nhóm bệnh nhân được phẫu thuật nội soi qua tiền đình miệng. Trong 30 bệnh nhẩn nghiên cứu của chúng tôi, độ tuổi trung bình là 29,3 $\pm 7,4$. Tất cả bênh nhân đều là nữ giới. Phần lớn bệnh nhân còn trẻ và là nữ giới đều có nhu cầu phẫu thuật tuyến giáp đảm bảo kết quả thẩm mĩ cao nhất. U bên phải chiếm $56,7 \%$, bên trái chiếm $43,3 \%$. Tất cả BN đều có mô bệnh học là UTTG thể nhú. Thời gian đầu mới bắt đâu triển khai kỹ thuật này, chúng tôi áp dụng chủ yếu cho những bệnh nhân lành tính. Hiện tại, chúng tôi đã áp dụng thường qui phương pháp này trong phâu thuật điều trị ung thư tuyến giáp tại Bệnh viện $K$. Trong 30 bệnh nhân, cắt một bền thuỳ tuyến giáp, eo kèm vét hạch nhóm 6 một bên được thực hiện trên 26 bệnh nhân ung thư tuyến giáp cT1NOMO ở một thuỳ tuyến giáp và 4 bệnh nhân ung thư còn lại được thực hiện cắt toàn bộ tuyến giáp kèm nạo vét hạch nhóm 6 hai bên. Kích thước u giáp trung bình là $7,4 \pm 3,3 \mathrm{~mm}$. Tất cả các bệnh nhân đều không có biểu hiện hạch cổ nghi ngờ di căn trên khám lâm sàng và siêu âm (cNO). Tuy nhiên sau phẫu thuật có tới 10 bệnh nhân có vi di căn hạch nhóm 6 sau phẫu thuật (chiếm 
33,3\%). Số lượng hạch trung bình vét được là $4,9 \pm 2,9$ hạch. Các hạch nhóm 6 di căn sau mổ đều có kích thước nhỏ $(<5 \mathrm{~mm})$ và số lượng hach di căn nhiều nhất là 4 hach nên các bềnh nhân này đều có chỉ định theo dối sau phẫu thuật.

Kết quả phẫu thuật sớm trong điêu trị UTTG thể nhú tại Bệnh viện K. Thời gian cắt một thuỳ, eo giáp và vét hach nhóm 6 cùng bên trung bình là 105,5 phút và cho nhóm cắt toàn bộ tuyến giáp kèm vét hạch nhóm 6 hai bên trung bình là 140,5 phút. Theo Ahn và cộng sự khi tiến hành nghiên cứu trên 275 bệnh nhân, trong đó có 150 bệnh nhân được làm qua TOETVA và 125 bệnh nhân được mổ mở cổ điển [4]. Kết quả cho thấy thời gian phẫu thuật ở nhóm bệnh nhân TOETVA cao hơn nhóm mổ mở. Điều này có thể dễ dàng giải thích là do phẫu thuật viên cần có thời gian để đặt trocars và tạo khoang khi phẫu thuật TOETVA. Rõ ràng, thời gian phẫu thuật TOETVA sẽ giảm dần theo thời gian khi phẫu thuật viên có kinh nghiệm. 30 bệnh nhân trong nghiên cứu của chúng tôi đều không đặt dẫn lưu sau phẫu thuật và cũng không có bệnh nhân nào tụ dịch sau mổ.

Số lượng hạch cổ trung tâm vét được trung bình trong nghiên cứu của chúng tôi là $4,9 \pm 2,9$ hạch. Theo Ahn và cộng sự (2020), kết quả cho thấy số lượng hạch nhóm 6 vét được giữa 2 nhóm không có sự khác biệt (3.19 \pm 2.89 vs. $3.49 \pm 2.41, p=0.319)$ [4].

Biến chứng sau phâu thuật. Trong nghiên cứu của chúng tôi, không có bệnh nhân nào phải chuyển mổ mở trong phẩu thuật, không có bệnh nhân nào chảy máu hậu phẫu. Chỉ có 2 bệnh nhân khàn tiếng tạm thời sau mổ và không có bệnh nhân nào khàn tiếng vĩnh viễn. Ngoài ra cũ̃ng không có bệnh nhân nào hạ canxi tạm thời, vĩnh viễn. Điều này có thể dễ dàng lý giải khi trong số 30 bệnh nhân chỉ có 4 bệnh nhân được cắt toàn bộ và chưa có bệnh nhân nào hạ canxi tạm thời. Theo Kim và cộng sự (2020) khi tiến hành phân tích trên 132 bệnh nhân, chỉ có 6 bệnh nhân khàn tiếng tạm thời, không có bệnh nhân nào khàn tiếng vĩnh viễn, hạ canxi sau mổ. Không có bệnh nhân nào chảy máu, chuyển mổ mơ [5].

Môt trong những biến chứng khác với mổ mở khi tiến hành TOETVA đó là biến chứng nhiễm trùng và tổn thương thần kinh cằm. Trong nghiên cứu của chúng tôi, không có bệnh nhân nào nhiễm trùng sau mổ và tỷ lệ bệnh nhân có tổn thương thần kinh cằm tạm thời là 6 bệnh nhân (chiếm $20 \%$ ) và chỉ có 1 bệnh nhân có tê bì vùng cằm và môi dưới kéo dài trên 3 tháng, sau 6 tháng mức độ tê bì cũng giảm dần và không ảnh hưởng tới chất lượng cuộc sống của bênh nhân. Trong phân tích gộp khi so sánh 2 nhóm TOETVA và mổ mở thì cũng không có sự khác biệt giữa tình trạng nhiếm trùng sau mổ giữa hai nhóm. Lý do có thể là bệnh nhân TOETVA đã được dùng kháng sinh dự phòng và được sát khuẩn khoang miệng sạch sẽ trước, trong và sau mổ [6]. Theo Russell và cộng sự (2020) khi tiến hành TOETVA trên 200 bệnh nhân ở Mỹ, chỉ có 2,5\% số bệnh nhân có tê bì ở cằm và môi dưới kéo dài trên 3 tháng [7]. Theo Wang và cộng sự khi tiến hành phân tích gộp trên 1151 bệnh nhân cũng cho kết quả tương tự khi tỷ lê bệnh nhân có tổn thương thần kinh cằm vĩnh viễn chỉ dưới $1 \%$ [6]. Như vậy, phương pháp TOETVA là một phương pháp mới tương đối an toàn.

Về kết quả thẩm mĩ, tất cả 30 bệnh nhân của chúng tôi đều hài lòng về kết quả thẩm mĩ sau phẫu thuật. Đây là một trong những ưu điểm vượt trội của phương pháp này. Do đó, trong thời gian tới, TOETVA sẽ là một xu hướng của trong phẫu thuật tuyến giáp ở Việt Nam cũng như trên thế giới.

\section{KẾT LUẬN}

Phẫu thuật nội soi tuyến giáp qua tiền đình miệng là một phương pháp an toàn, hiệu quả, đạt kết quả thẩm mĩ tối ưu trong điêu trị ung thư tuyến giáp. Tuy nhiên đối với $B N$ ung thư tuyến giáp, cân có thời gian theo dõi dài hơn để đánh giá về kết quả ung thư học. Mặc dù vậy, TOETVA là một cách tiếp cận đầy hứa hẹn và nên được triển khai rộng rãi trong tương lai.

\section{TÀI LIÊU THAM KHẢO}

1. Russell JO, Sahli ZT, Shaear M, Razavi C, Ali K, Tufano RP. Transoral thyroid and parathyroid surgery via the vestibular approach-a 2020 update. Gland Surg 2020;9(2):409-416. doi: 10.21037/gs.2020.03.05

2. Anuwong A. Transoral endoscopic thyroidectomy vestibular approach: a series of the first 60 human cases. World J Surg. 2016;40(3):491-497.

3. Le QV, Ngo DQ, Ngo QX. Transoral endoscopic thyroidectomy vestibular approach (TOETVA): A case report as new technique in thyroid surgery in Vietnam. Int J Surg Case Rep. 2018;50:60-63

4. Ahn JH, Yi JW. Transoral endoscopic thyroidectomy for thyroid carcinoma: outcomes and surgical completeness in 150 single-surgeon cases. Surg Endosc. 2020 Feb;34(2):861-867

5. Kim SY, Kim SM, Makay Ö, Chang H, Kim BW, Lee YS, Park CS, Chang HS. Transoral endoscopic thyroidectomy using the vestibular approach with an endoscopic retractor in thyroid cancer: experience with the first 132 patients. Surg Endosc. 2020 Dec;34(12):5414-5420 
6. Wang $Y$, Zhou $S$, Liu $X$, et al. Transoral endoscopic thyroidectomy vestibular approach vs conventional open thyroidectomy: Meta-analysis. Head \& Neck. 2020; 1-9

7. Russell J0, Razavi CR, Shaear M, Liu RH,
Chen LW, Pace-Asciak P, Tanavde V, Tai KY, Ali K, Fondong A, Kim HY, Tufano RP. Transoral Thyroidectomy: Safety and Outcomes of 200 Consecutive North American Cases. World J Surg. 2021 Mar;45(3):774-781

\section{ĐÁNH GIÁ HIỆU QUẢ BỔ SUNG LỢI KHUẨN LACTOBACILLUS CASEI SHIROTA (LCS) TRÊN TRẺ 3 - 5 TUỔI BI TÁO BÓN CHỨC NĂNG TÁI 4 XÃ, TỈNH THANH HÓA}

\begin{abstract}
TÓM TĂT
Mục tiêu: Đánh giá hiệu quả bổ sung lợi khuẩn Lactobacillus casei Shirota lền cải thiện tình trạng táo bón của trẻ $3-5$ tuổi bị táo bón chức năng. Phương pháp: Nghiên cứu can thiệp cộng đồng, ngấu nhiên, có đối chứng trên 216 trẻ bị táo bón chức năng tại 4 xã thuộc 2 huyên Yên Đinh và Nông Cống, tỉnh Thanh Hóa được chia làm 2 nhóm (nhóm can thiệp và nhóm chứng). Các triệu chứng táo bón được thu thập trước, trong và sau can thiệp. Kết quả: Sau 12 tuân can thiệp: số lần đại tiện/1 tuần ở nhóm can thiệp tăng lên 0,5 lần so với ban đầu, ở nhóm chứng không có sự cải thiện. Tỷ lệ trẻ có phân dạng 2 ở nhóm can thiệp là $5,6 \%$ và $35,2 \%$ phân dạng 3 , nhóm chứng là $8,3 \%$ phân dạng 2 và $41,7 \%$ phân dạng 3 . Tỷ lệ són phân của trẻ ở nhóm can thiêp là $2,8 \%$ và $3,7 \%$ ở nhóm chứng, có sự cải thiện tổt hơn về tỷ lệ nhịn đi đại tiện ở nhóm can thiêp so với nhóm chứng. Tỷ lê trẻ có triệu chứng phân cứng, phân to giảm rõ rệt so với nhóm chứng. Kết luân: Tình trang táo bón của trẻ 3 5 tuổi bị mắc táo bón chức năng được cải thiện sau can thiêp bằng lợi khuẩn Lactobacillus casei Shirota.
\end{abstract}

Tư khóa: Lactobacillus casei chủng Shirota, táo bón chức năng, trẻ em.

\section{SUMMARY \\ THE EFFECT OF LACTOBACILLUS CASEI \\ SHIROTA (LCS) SUPPLEMENTED ON IMPROVEMENT CONSTIPATION IN CHILDREN 3-5 YEARS OLD SUFFERING FUNCTIONAL CONSTIPATION}

Objectives: To evaluate the effect of lactobacillus casei shirota (ICS) supplemented on improvement constipation in children 3-5 years old suffering functional constipation. Method: A controlled field trial was conducted with 216 children with functional constipation in 4 communes in 2 districts of Yen Dinh and Nong Cong, Thanh Hoa province were divided into

\footnotetext{
${ }^{1}$ Trường Đại học Y Dược Hải Phòng

${ }^{2}$ Viện Dinh dướng

Chịu trách nhiệm chính: Phạm Thị Thư

Email: ptthu@hpmu.edu.vn

Ngày nhận bài: 20.9.2021

Ngày phản biên khoa hoc: 15.11.2021

Ngày duyệt bài: 24.11.2021
}

Phạm Thị Thưr ${ }^{1}$ Trương Tuyết Mai ${ }^{2}$, Nguyễn Ngọc Sáng1, Hoàng Thị Hằng ${ }^{2}$

2 groups (control group and intervention group). Results: After 12 weeks of intervention: the number of bowel movements/week in the intervention group increased by 0,5 times compared to baseline, in the control group there was no improvement. The percentage of children with type 2 stool consistency in the intervention group was 5,6\% and 35,2\% with type 3 stool consistency, the control group was $8,3 \%$ with type 2 stool consistency and 41,7\% with type 3 stool consistency. The rate of fecal incontinence in the intervention group was $2,8 \%$ and $3,7 \%$ in the control group. There was a better improvement in the rate of excessive stool retention in the intervention group compared with the control group. The percentage of children with symptoms of hard stools and large stools was significantly reduced compared with the control group. Conclusion: Functional constipation in children with 3 to 5 years old was improved after interventing with Lactobacillus casei Shirota.

Keywords: Lactobacillus casei Shirota, functional constipation, children

\section{I. ĐĂT VẤN ĐỀ}

Táo bón là một tình trạng rối loạn tiêu hóa thường gặp ở trẻ em. Đây là vấn đề sức khoẻ cộng đồng ngày càng tăng trên toàn thế giới có tác động đáng kể đến y tế, xã hội và kinh tế. Nguyền nhân gây táo bón rất đa dạng nhưng chủ yếu táo bón do nguyên nhân chức năng chiếm $90-95 \%$ [1]. Tỷ lệ mắc táo bón chức năng ở trẻ em dao động từ $0,7 \%-29 \%$ ở cả các nước đã và đang phát triển [2]. Tại Việt Nam, táo bón trẻ em vẩn còn là một vấn đề chưa được quan tâm đúng mức. Nghiên cứu của Nguyễn Thị Phương Mai trên 137 trẻ táo bón đến khám tại bệnh viện Nhi Trung Ương có $92,5 \%$ trẻ mắc bểnh táo bón chức năng [3]. Táo bón chức năng nếu không được theo dõi và điều trị hợp lý, tình trạng táo bón kéo dài sẽ dẫn đến trẻ bị suy dinh dưỡng. Lactobacillus casei chủng Shirota (LCS) được nghiên cứu tại nhiều quốc gia và hiệu quả của LCS trong phòng và điêu trị táo bón cũng được ghi nhận ở nhiều nghiên cứu trên các đối tượng khác nhau. Tuy nhiên, hiệu quả của lợi 